\title{
TREATMENT OF DISPERSED IRON-BEARING RAW MATERIALS AND MODELING OF THE PROTECTION SYSTEMS AGAINST AIR- POLLUTION
}

\author{
Zoran Anđićl ${ }^{*}$, Marija Korać ${ }^{2}$, Željko Kamberović $^{2}$ \\ ${ }^{1}$ Innovation Center of the Faculty of Chemistry, University of Belgrade, \\ Studentski Trg 12-16, 11000 Belgrade, Serbia \\ ${ }^{2}$ Faculty of Technology and Metallurgy, University of Belgrade, Karnegijeva 4, \\ 11120 Belgrade, Serbia
}

Received 14.12.2016

Accepted 30.12.2016

\begin{abstract}
Based on the analysis of the non-standard iron-bearing raw materials treatment process and the results of real composition measurements of the flue gas, the study of hazards by identification of harmful substances that occur in the accident, as well as the modeling of the system of protection against air-pollution due to the cancellation of work the bag filter was carried out. Applying the model (Aloha software package) provides an overview of possible developments of events and zones of propagation of the precipitated particulate matter through the share of cadmium $(\mathrm{Cd})$ in them. In the case of malfunction of filter system, emissions of particulate matter enormously exceed the permitted values. In the conditions of the simulated accident, particle velocity of flue gases was amounted $\mathrm{E} \approx 738 \mathrm{mg} / \mathrm{s}$ or $2657 \mathrm{~g} / \mathrm{h}$ of dust. The propagation of the precipitated particulate matter in the lower layer of the atmosphere, downwind, given trough the share of $\mathrm{Cd}$ in them, is $100 \mathrm{~m}$ from the source of pollution for the characteristic density of $5 \mu \mathrm{g} / \mathrm{m}^{2}$.day and $140 \mathrm{~m}$ for the characteristic density of 2 $\mu \mathrm{g} / \mathrm{m}^{2}$.day, in the stable state of the atmosphere, i.e. $870 \mathrm{~m}$ and $1100 \mathrm{~m}$, respectively, in the neutral state of the atmosphere.

Keywords: Modeling, Electric arc furnace dust, Hazardous waste, Accident
\end{abstract}

\section{Introduction}

As one of the major industrial sector, secondary steel production generates large amounts of dust and slag containing iron, zinc, lead, chromium, nickel and molybdenum. By its composition, theses wastes consist of stable oxides: $\mathrm{CaO}, \mathrm{SiO}_{2}$,

\footnotetext{
* Corresponding author: Zoran Anđić, zoranandjic@yahoo.com
} 
$\mathrm{Al}_{2} \mathrm{O}_{3}$, iron oxide, chromium, nickel, molybdenum, manganese, magnesium, phosphorus, and others, as well as evaporable metals $\mathrm{Zn}, \mathrm{Pb}$ and $\mathrm{Cd}$. Due to the presence of pollutants and their mobility into the environment, this waste falls into the category of hazardous waste. However, in some cases, the metal content is relatively high, so from an economic perspective, treatment of this type of waste is very costeffective, especially if contain significant amounts of zinc, nickel, chromium and molybdenum $[1,2]$.

Electric-arc furnace dust (EAFD) from the production of steel is considered hazardous waste due to the high alkalinity and high content of heavy metals. They represent a complex material, which contains large amounts of zinc and lead, as well as significant amounts of $\mathrm{Ca}, \mathrm{Mn}, \mathrm{Mg}$, and $\mathrm{Cr}$, so they cannot be landfilled without treatment. Emission of the generated waste in the environment can lead to environmental pollution, therefore the controlled delivery process and proper waste management are foundation to preserve the environment from pollution originating from industrial steel production.

DC plasma arc furnace technology has been successfully used in many metallurgical applications such as: melting of iron units (DRI or scrap), smelting reduction of chrome fines for $\mathrm{FeCr}$ production, smelting reduction of ilmenite for titanium slag production, smelting reduction of EAF dust for recovery of $\mathrm{Cr}, \mathrm{Ni}, \mathrm{Mo}$ and $\mathrm{Zn}$ and metal recovery from other metal-containing wastes [3, 4].

Due to the large number of components, variable parameters and fast kinetics of the process, it is difficult to keep track of the process flow in DC plasma furnace. Also, during the process of melting and casting there are many possible accident situations, which may lead to uncontrolled release of waste gases into the working, and then in the living environment [1].

In the last decades, much has been done to reduce air pollution. Many international and European regulatory bodies have been dealing with this topic, and all documents which have been adopted are aimed at achieving long-term goals of environmental protection and the development of more efficient systems for gathering information, modeling and forecasting of air-pollution [5-9].

According to Article 5 of the Stockholm Convention on Persistent Organic Pollutants, each party has the obligation to take measures to reduce to the minimum total accidental discharges from anthropogenic sources of the following chemicals listed in Annex $\mathrm{C}$ of the Convention: polychlorinated dibenzo-p-dioxins and dibenzo- furans PCDD/PCDF, hexachlorobenzene $\mathrm{HCB}, \mathrm{PeCB}$ penta-hlorbenzen and poly- chlorinated biphenyls PCBs [5].

The uncontrolled emission of pollutants from the production process may lead to serious negative impacts to the environment, because same may easily migrate into groundwater, and finally through soil and crops directly inhaled by humans and animals. [9].

According to state above, non-standard waste materials based on iron and zinc obtained by melting iron-bearing waste in the EAF steel production, are melted, with the addition of other synergetic by-products and waste, in DC plasma furnace $[1,2]$. Obtained results of material balance and composition, as well as the results of real measurements of the flue gas composition were used to identify hazardous/harmful substances that can occur during accidents. The applied model (Aloha software package) provides the overview of possible event developments due to the malfunction 
of bag filter and zones propagation of the precipitated particulate matter through the share of cadmium in them.

\section{Experimental part}

Treatment of EAFD in selected technological environment was carried out in a plasma arc furnace with the aim of the $\mathrm{Zn}$ valorization with at the same time the stabilization of waste. In this way, a higher level of valorization of useful components of EAFD could be achieved, primarily Fe through the pig iron and Zn through the dust.

Figure 1 gives an overview of the applied technological process of treatment of non-standard disperse iron-bearing raw materials using plasma arc melting.

EAFD generated in the secondary steel production is mixed with mill scale, pyrite cinder, magnetite, coke, lime and cement in certain relations. The mixture was pelletized and dried on the air. After mixing the components, the obtained pellets were annealing in $100 \mathrm{~kW}$ pilot plant DC-plasma arc furnace with the capacity of $150 \mathrm{~kg}$ of charge.

In the previously published research works of the authors, the characterization of the utilized raw materials, composition of pellets and chemical analysis of the products of annealing is presented $[1,10,11]$.

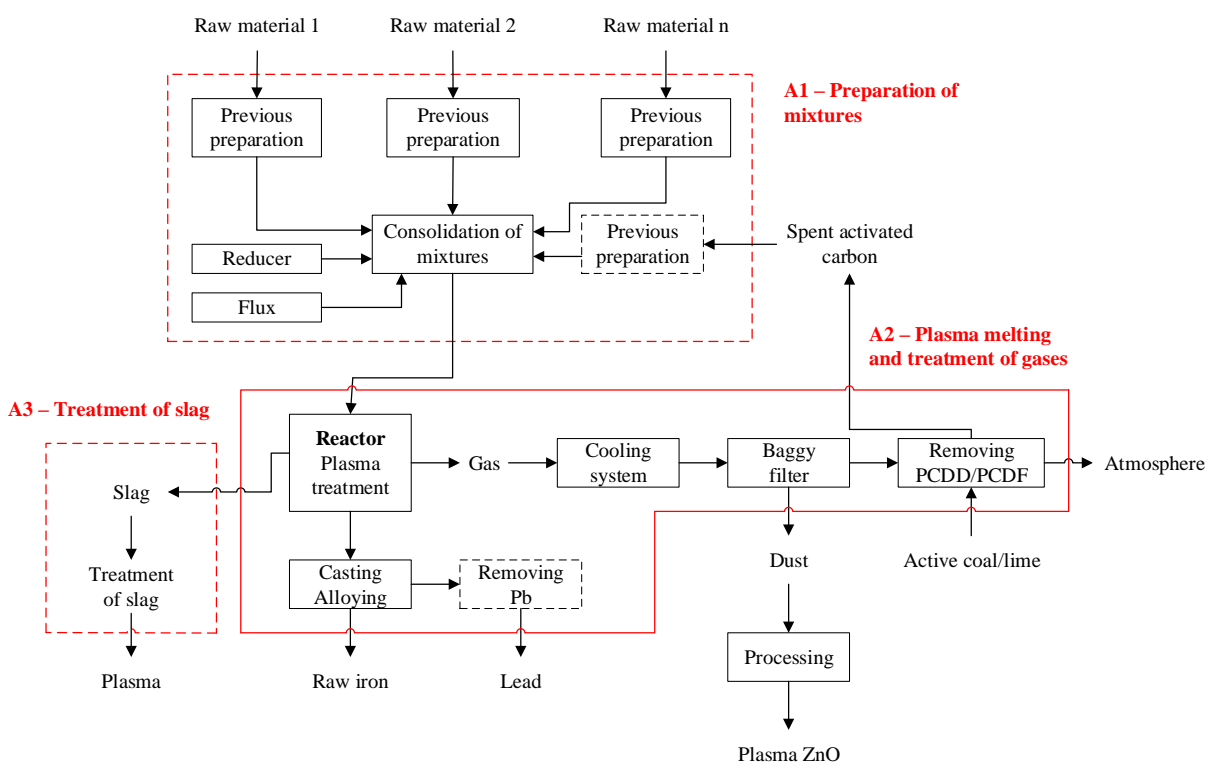

Fig. 1. The technological process for the treatment of non-standard disperse iron-bearing raw materials using plasma arc melting

The gaseous products are transferred from the furnace through the off-gas system and formed $\mathrm{ZnO}$ dust is collected in a bag filter. In order to prevent the emission of harmful pollutants, i.e. removing PCDD/PCDF, exhaust gases, after bag filter, passed through the chamber with layers of activated carbon and lime (Fig. 1.). The composition of the gases was measured using the Testo 340 Flue gas analyzer, whereat $\mathrm{CO}, \mathrm{NO}_{\mathrm{x}}$ and 
$\mathrm{SO}_{2}$ are measured. The gas composition is presented in the previously published research works of the authors [1].

Based on the analysis of the technological process and the results of real measurements of the off-gas composition, the analysis of hazards by identification of harmful substances that occur in the accident, as well as the modeling of the system of protection against air-pollution due to the malfunction of bag filter was carried out using the Aloha software package. Applying the model provides an overview of possible developments of events and zones of propagation of the precipitated particulate matter through the share of cadmium $(\mathrm{Cd})$ in them.

\section{Results and discussion}

Emissions of $\mathrm{CO}, \mathrm{NO}_{\mathrm{x}}$ and $\mathrm{SO}_{2}$ were measured in real conditions during three periods of the melting process [1]:

I charging the batch at low temperature in the furnace,

II melting the batch with increasing the furnaces temperature, and

III harging the batch at high temperature in furnace.

In the first period, at the beginning of the smelting process, temperatures are relatively low, below $600{ }^{\circ} \mathrm{C}$. Accordingly, the carbon-monoxide was not produced. It was confirmed by HSC simulation, whose results were presented in the previous article of the authors [1]. Also, during this period of the process higher share of $\mathrm{NO}_{\mathrm{x}}$ and $\mathrm{SO}_{2}$ was recorded. Sulfur from the charge was released and reacted with oxygen, but soon it is exhausted due to its low content in the pellets, as it is obviously in the period two. In the period two temperatures are increasing and carbon-monoxide was realized, so its content will increase with time. Reduction atmosphere in the furnace does not allow formation of $\mathrm{NO}_{\mathrm{x}}$. At period three, high temperatures are achieved and new amount of charge was inserted into the furnace. The sulfur content is much lower than in first period and it decrease with the time until it is excluded from the pellets. Due to rapid carbon reaction with metal oxides, content of CO-gas was high and then it was decreasing over time of this period, because carbon content in the pellets was reduced. At the end of this period pellets are melted and liquid metal and slag are formed.

During the treatment of non-standard iron-bearing disperse raw materials in the DC plasma arc furnace accidental situation may occur, which, bearing in mind the results of measurements of the composition of gas, can cause acute pollution both working and living environment. Based on the analysis of the technological process and the results of examination of the product composition of melting, hazards have been identified with the separate accidental situations due to the cancellation of work the bag filter, which can cause an emission of dust known composition.

The same process has been analyzed, but for a much larger production capacity electric arc furnace for smelting steel capacity of $50 \mathrm{t} / \mathrm{h}$.

The most common accident scenario that is linked to the system for gas purification is his cessation of work due to mechanical failure, causing an uncontrolled scattering of particles of dust and chips in the amount of $7.07 \mathrm{~kg}$ for 30 minutes during the accident or dust concentrations of $37.7 \mathrm{mg} / \mathrm{m}^{3}$. Regarding to this, it is necessary to assess the distribution of concentration of hazardous (harmful) substances in the ambient air and the density of precipitated particles on the ground. 
The input data for modeling the effects of accidents:

1. Characteristics of stack:

- Height of the stack $\mathrm{H}=35 \mathrm{~m}$

- The size of the inner diameter of the stack (the size of light opening): $\mathrm{D}=3.8 \mathrm{~mm}$

2. Characteristics of the flue gases:

- $\quad$ Average temperature of the flue gases at the outlet from the stack: $T_{a} \approx$ $90{ }^{\circ} \mathrm{C}$

- Medium velocity of flue gases: $v_{\mathrm{dg}} \approx 15.5 \mathrm{~m} / \mathrm{s}$

- Volume flow of flue gas (secondary line): $\dot{V}=7.5 \cdot 10^{5} \mathrm{Nm}^{3} / \mathrm{h}$.

3. Characteristics of particulate matter (Tables 1 and 2)

Table 1. Composition of particular matter, weight \%

\begin{tabular}{lcccccc}
\hline Component & FeO & $\mathbf{Z n O}$ & $\mathbf{C d O}$ & $\mathbf{P b C l}_{2}$ & $\mathbf{C u C l}$ & $\mathbf{C}$ \\
\hline Share, $\mathbf{m} / \mathbf{m}, \boldsymbol{\%}$ & 7.20 & 78.20 & 3.48 & 0.07 & 0.32 & 1.87 \\
\hline
\end{tabular}

Table 2. The mean particle diameter

\begin{tabular}{cccc}
\hline $\begin{array}{c}\text { The mean } \\
\text { particle } \\
\text { diameter }(\mathbf{m m})\end{array}$ & $\mathbf{m} / \mathbf{m}, \boldsymbol{\%}$ & $\begin{array}{c}\text { The mean particle } \\
\text { diameter }(\mathbf{m m})\end{array}$ & $\mathbf{m} / \mathbf{m}, \boldsymbol{\%}$ \\
\hline 5.0 & 18.0 & 0.40 & 4.8 \\
2.5 & 9.0 & 0.315 & 6.2 \\
2.0 & 3.0 & 0.25 & 2.0 \\
1.8 & 3.0 & 0.125 & 16.5 \\
1.25 & 3.5 & 0.10 & 4.0 \\
1.0 & 1.5 & 0.09 & 1.0 \\
0.8 & 4.5 & 0.08 & 0.7 \\
0.63 & 19 & 0.07 & 1.3 \\
0.50 & 2.0 & - & - \\
\hline
\end{tabular}

4. Anticipated weather conditions:

- Ambient air temperature: $20^{\circ} \mathrm{C}$,

- The lower layer of the atmosphere state (two variants considered):

- Stable (stability class F), with a wind speed of $1.5 \mathrm{~m} / \mathrm{s}$ (at a height of 10 $\mathrm{m})$,

- $\quad$ Neutral (stability class D), with a wind speed of $3 \mathrm{~m} / \mathrm{s}$ (at a height of 10 $\mathrm{m})$,

- Surrounding ground: open, flat.

For listed conditions of the simulated accident, particle velocity of flue gases was calculated (emissions) $\mathrm{E} \approx 738 \mathrm{mg} / \mathrm{s}$ or $2657 \mathrm{~g} / \mathrm{h}$ of dust. Emission limit value of cadmium and its compounds as carcinogens first class is $0.05 \mathrm{mg} / \mathrm{Nm}^{3}$ for the mass flow in waste gas of $0.15 \mathrm{~g} / \mathrm{h}$ and higher [12].

For the dispersion of particulate matter in the ambient atmosphere a mathematical model has been applied based on the statistical theory with Gaussian distribution, with the following corrections in order to obtain real results: 
- For change the wind speed with height, the so-called 'the degree of legality' is applied:

$$
v=v_{10}\left(\frac{z}{10}\right)^{p}
$$

- Raising the starting current of flue gases (after leaving the stack) was calculated on the basis of known equations (1), with obtaining the following results $[13,14]$ :

- for stability class $\mathrm{F}: \Delta H \approx 54.8 \mathrm{~m}$,

- for stability class $\mathrm{D}: \Delta H \approx 93.7 \mathrm{~m}$,

- Coefficient of dispersion of the dispersing components $\left(\sigma_{y}\right.$ and $\left.\sigma_{z}\right)$, in the direction of $\mathrm{y}$ - and $\mathrm{z}$-axes were calculated using the recommended formula for the continuous discharges in an open field (2), corrected for the initial value of dispersion, according to the following dependencies:

$$
\sigma_{y o}=\frac{D}{4,3} \quad \text { and } \quad \sigma_{z o} \approx\left(\frac{E}{\rho \cdot \pi \cdot v_{1}}\right)^{0,5}
$$

The deposition rate of powder particles was calculated by applying the law of Stokes, with the introduction of correction factors for the finer particles (2):

$$
v_{g}=\frac{\left(\rho_{p m}-\rho_{a}\right) \cdot g \cdot D_{p m}^{2}}{18 \cdot \mu} \cdot S_{C F}
$$

where is:

- $\rho_{p m}-$ average density of particulate matter, $\mathrm{kg} / \mathrm{m}^{3}\left(\mathrm{ppm} \approx 5607 \mathrm{~kg} / \mathrm{m}^{3}\right)$

- $\quad \rho_{a}$ - air density, $\mathrm{kg} / \mathrm{m}^{3}$

- $D_{p m}$ - the diameter of a powdery substance, $\mathrm{m}$

$\mu \quad$ - the viscosity of air, $\mathrm{Pa} \cdot \mathrm{s}$

- $\quad S_{C F}$ - empirical factor: $S_{C F}=1+0,16 / \mathrm{D}_{\mathrm{pm}}, \quad\left(\mathrm{D}_{\mathrm{pm}}\right.$ in $\left.\mu \mathrm{m}\right)$

For the hazard assessment, i.e. giving an estimate of the threat to the environment in this case is much more important share of precipitated particles than the share of particles that form a concentration profile in the air, because it is not respirable particles. These are large dispersed particles that are contaminants primarily of surrounding soil.

The relevant values of characteristic zones of the deposited particulate matter for assessment of the risk against contamination of the surrounding soil were derived for cadmium $(\mathrm{Cd})$ as most toxic and most cancerous component of the present in the chemical composition of particulate matter (Figure 2):

- for uninhabited areas: $2 \mu \mathrm{g} / \mathrm{m}^{2}$.day

- for inhabited areas $5 \mu \mathrm{g} / \mathrm{m}^{2} \cdot$ day. 
Figure 2 shows the zone propagation of deposited particulate matter, given through the share of $\mathrm{Cd}$ in them, downwind, for the cancellation of the work of the filter system, for a period of $30 \mathrm{~min}$ for different conditions in the lower layer of the atmosphere.

For the stable state of the atmosphere F1,5, the propagation of the precipitated particulate matter in the lower layer of the atmosphere, downwind, given trough the share of $\mathrm{Cd}$ in them, is $100 \mathrm{~m}$ from the source of pollution for the characteristic density of $5 \mu \mathrm{g} / \mathrm{m}^{2} \cdot$ day and $140 \mathrm{~m}$ for the characteristic density of $2 \mu \mathrm{g} / \mathrm{m}^{2} \cdot$ day. The propagation of the precipitated particulate matter in the lower layer of the atmosphere, downwind, given trough the share of $\mathrm{Cd}$ in them, is $870 \mathrm{~m}$ from the source of pollution for the characteristic density of $5 \mu \mathrm{g} / \mathrm{m}^{2}$.day and $1100 \mathrm{~m}$ for a characteristic density of 2 $\mu \mathrm{g} / \mathrm{m}^{2}$.day, for the neutral state of the atmosphere D3.
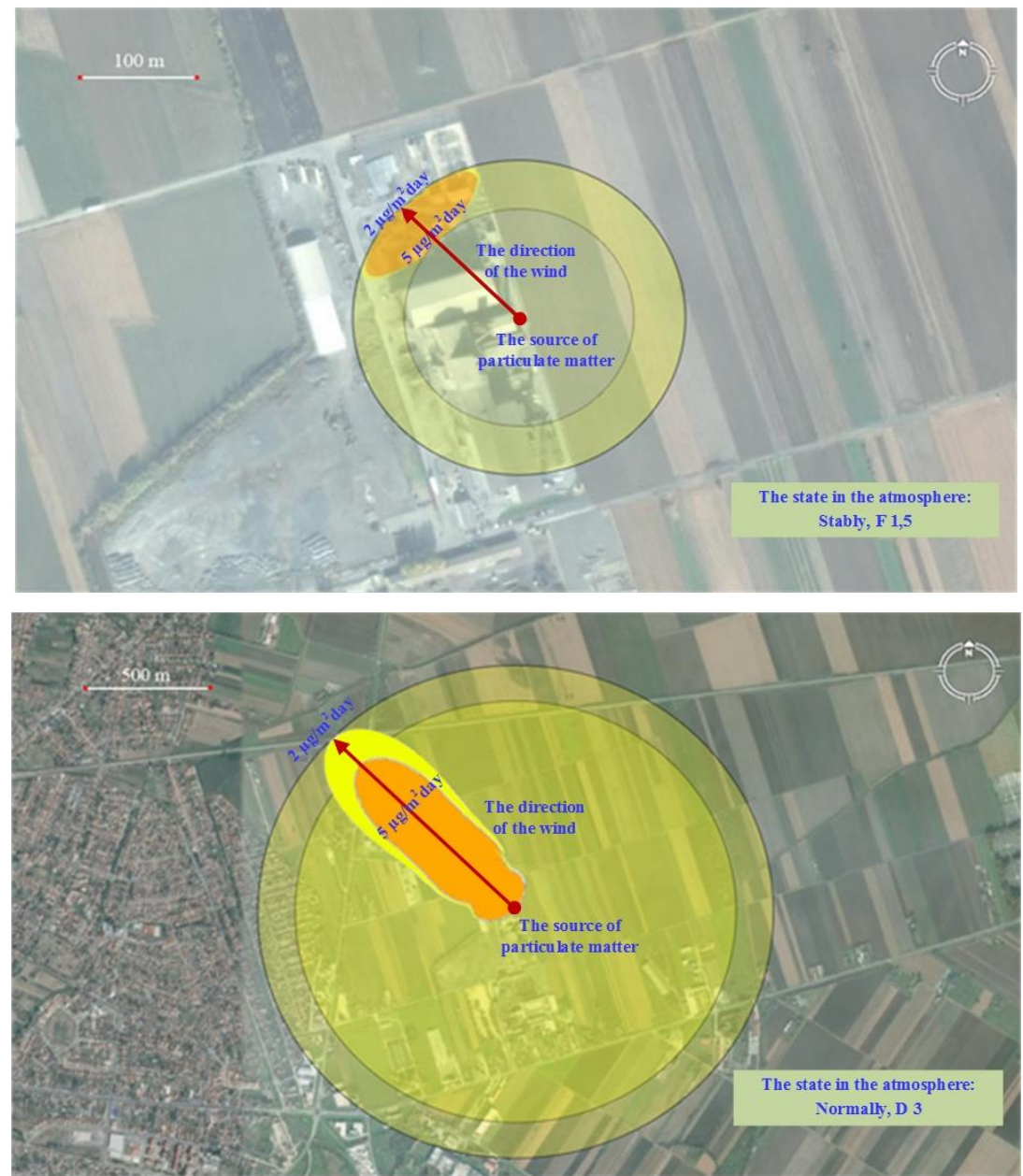

Fig. 2. The zone propagation of deposited particulate matter, given through the share of Cd in them 


\section{Conclusion}

Based on the analysis of the technological process of melting of non-standard iron-bearing raw materials and the results of real measurements composition of the flue gas have been identified hazards by detection of harmful substances which are resulting in the accident. The applied model provides the overview of possible developments events due to the cancellation of work bag filter and zones propagation of the precipitated particulate matter through the share of cadmium in them.

The process of dispersion of dust in terms of regular operation of the filter system is simulated and does not perceive the zone propagation of characteristic levels of the pollution, which are characteristic in case of an accident. It is evident that in case of malfunction of work filter system, emissions of particulate matter enormously exceed the permitted values. For conditions of the simulated accident, particle velocity of flue gases was calculated (emissions) $-\mathrm{E} \approx 738 \mathrm{mg} / \mathrm{s}$ or $2.657 \mathrm{~g} / \mathrm{h}$ of dust. Emission limit value of cadmium and its compounds as carcinogens first class is $0.05 \mathrm{mg} / \mathrm{Nm}^{3}$ for the mass flow in waste gas of $0.15 \mathrm{~g} / \mathrm{h}$ and higher.

In the stable state of the atmosphere F1,5, the propagation of the precipitated particulate matter in the lower layer of the atmosphere, downwind, given trough the share of $\mathrm{Cd}$ in them, is $100 \mathrm{~m}$ from the source of pollution for the characteristic density of $5 \mu \mathrm{g} / \mathrm{m}^{2}$.day and $140 \mathrm{~m}$ for the characteristic density of $2 \mu \mathrm{g} / \mathrm{m}^{2} \cdot$ day. The propagation of the precipitated particulate matter in the lower layer of the atmosphere, downwind, given trough the share of $\mathrm{Cd}$ in them, is $870 \mathrm{~m}$ from the source of pollution for the characteristic density of $5 \mu \mathrm{g} / \mathrm{m}^{2}$.day and $1100 \mathrm{~m}$ for the characteristic density of 2 $\mu \mathrm{g} / \mathrm{m}^{2} \cdot$ day, in the neutral state of the atmosphere D3.

Using the best available technologies and through the adequate management and controlling material flows in the production process, monitoring the quality of air, soil and water flows, provides a good approach to planning and assessment of the occurrence of accidents and adverse events in the treatment of non-standard disperse iron-bearing raw materials. The assessment of the probability of accident, risk assessment and the possible consequences for the working and living environment with the planning measures for response to accidents will be the subject of future research.

\section{Acknowledgement}

This research was financially supported by the Ministry of Education, Science and Technological Development of the Republic of Serbia and is a result of project No. 34033.

\section{References}

[1] V. Manojlović, Ž. Kamberović, M. Simić, D. Ivšić-Bajčeta, M. Korać, M. Pavlović, A. Tomović, In: Proceedings „ECOLOGY OF URBAN AREAS 2013“, Eds.: M. Pavlović, University of Novi Sad, Faculty of Technical Sciences "Mihajlo Pupin" Zrenjanin 2013, p.143-148

[2] H. Issa, Ž. Kamberović, M. Gavrilovski, M. Korać, Z. Anđić, In: Proceedings ROMAT 2012, Politechnica University of Bucharest materials science and engineering faculty, Bucharest, Romania, 2012, p. 21-25

[3] MacRae, D. R.: Plasma Chemistry and Plasma Processing, 9(1), 1989, 85-118

[4] Mihovsky, M.: Journal of the University of Chemical Technology and Metallurgy, 45 (1), 2010, 3-18 
[5] The Stockholm Convention on Persistent Organic Pollutants, Category metallurgy, Association of metallurgical engineers of Serbia, Belgrade, 2011

[6] European Environment Agensy, EMEP/EEA air pollutant emission inventory guidebook 2013., Luxenbourg, 2013

[7] Directive 2008/50/EC of the European parliament and of the council of 21 May 2008.on ambient air quality and cleaner air for Europe, Official Journal of the European Union, L152

[8] Commission of the European communities, The communication on thematic Strategy on air pollution and The Directive on "Ambient air quality and cleaner air for Europe“, Brisel 2005, SEC 1133

[9] European commission, Integrated Pollution Prevention and Control Reference Document on Best Available Techniques for the Waste Treatments Industries, 2006

[10] H. Issa, M. Korać, M. Gavrilovski, M. Pavlović, Ž.Kamberović, Revista Chimie 63 (2012) 10, 1008-1012.

[11] Marko Filipović, Ţeljko Kamberović, Zoran AnĊić, Marija Korać, Milan Pavlović, In: Proceedings „ECOLOGY OF URBAN AREAS 2013“, Eds.: M. Pavlović, University of Novi Sad, Faculty of Technical Sciences "Mihajlo Pupin” Zrenjanin 2013, p.262-268

[12] The Regulation on limit values for emissions of pollutants in the air, Official Gazette of the Republic of Serbia, 71/10 and 6/11

[13] M. Assael, K. Kakosimos, CRP Press - Taylor Francis Group, New York, 2010

[14] Guidelines for Use of Vapor Cloud Dispersion Models, Secon edition, Center for Chemical Process Safety of the AIChE, New York, 1996 